\title{
THE IMPORTANCE OF CLINICAL TARGET VOLUME FOR RADIATION THERAPY IN RECTAL CANCER
}

\author{
Maria-Gabriela Aniţei ${ }^{凶}$, V. Scripcariu \\ University of Medicine and Pharmacy „Gr.T. Popa” Iaș i \\ First Surgical Oncology Unit, Regional Institute of Oncology Iaşi, Romania
}

\begin{abstract}
THE IMPORTANCE OF CLINICAL TARGET VOLUME FOR RADIATION THERAPY IN RECTAL CANCER (Abstract): Neoadjuvant chemoradiotherapy is the standard treatment in locally advanced rectal cancer and it was demonstrated that radiation therapy associated with total mesorectal excision reduces local recurrence rate. It is very important to precisely determine the area that is subjected to radiation, in order to avoid side effects. The clinical target volume (CTV) is dependent on tumor location, lymphatic drainage area and the degree of tumor invasion into nearby organs. The CTV determination must take into account the internal organ motion during the treatment. The radiotherapy simulating is possible due to specialized CT and/or MRI and planning software. Using this method, it is possible to modulate the intensity of radiation on tumor tissue, with minimal effects on normal tissues.
\end{abstract}

KEY WORDS: RECTAL CANCER; NEOADJUVANT CHEMORADIOTHERAPY; RADIOTHERAPY; TOTAL MESORECTAL EXCISION; CLINICAL TARGET VOLUME

SHORT TITLE: Target volume for radiation therapy in rectal cancer

HOW TO CITE: Anitei MG, Scripcariu V. The importance of clinical target volume for radiation therapy in rectal cancer. Jurnalul de chirurgie (Iaşi). 2013; 9(4): 315-319. DOI: 10.7438/1584-9341-9-4-2.

\section{INTRODUCTION}

Colorectal cancer rests the third most common cancer in both sexes in Europe, after prostate and breast cancers [1,2]. Approximately $30 \%$ of all colorectal cancers are diagnosed in the rectum $[1,2]$.

In the last three decades, cancer of the rectum has seen many developments both in terms of method of diagnosis and treatment: mesorectal surgery (total mesorectal excision, TME), postoperative chemotherapy and preoperative chemoradiotherapy. At the beginning of 2000s, preoperative chemoradiotherapy followed by becomes the new standard in the treatment of low-lying locally advanced rectal cancer [3].

Currently, the management of rectal cancer requires an individualized, multidisciplinary approach. Multidisciplinary team meetings significantly influence decision for staging methods, neoadjuvant treatment, sphincter saving surgery and adjuvant treatment. This review discusses the indications of the radiotherapy, different treatment schedules and the important of preoperative target volume in radiotherapy in low rectal cancer.

\section{RADIOTHERAPY'S INDICATIONS}

Since 1975, controlled trials, especially in United States, showed that postoperative chemoradiotherapy decreased rates of local recurrence and increased the likelihood of survival compared with surgery alone in patients with stages II and III rectal cancer [4]. In the same period, in Europe several studies were conducted on the preoperative radiotherapy in patients with resectable rectal cancer and without metastasis [5,6].

\footnotetext{
Received date: 28.06 .2013

Accepted date: 31.07 .2013

Correspondence to: Maria-Gabriela Aniţei, MD

Clinica I Chirurgie Oncologică, Institutul Regional de Oncologie Iaşi

Str. General Henry Mathias Berthlot nr. 2-4, 700483, Iaşi

Tel.: 0040 (0) 374278810

Fax: 0040 (0) 374278802

E-mail: dr.mgabriela@gmail.com
} 
Two treatment regimens have been proposed: short schedule radiotherapy (25 Gy in five fractions), followed by surgery within a week (the Swedish study) [3,7] and long schedule radiotherapy (50,4 Gy divided in 5 weeks) with surgery performed after 5-6 weeks (the Polish study) [8].

The advantages of preoperative radiation include: reduction of local recurrence; rectal tumor down staging; possible sphincter preservation due to reduction in tumor size; less irradiation of small bowel and, therefore, less acute toxicity; irradiation of well-oxygenated tissues and theoretically greater eficacy; avoidance of radiation of the "neorectum".

\section{1) Reduction of local recurrences}

The first and primary indication for neoadjuvant radio(chemo-)therapy in lowlying locally advanced rectal cancer, in addition to surgery is to prevent local recurrences. The radiotherapy may prevent the growth of cancer cells, which are not excised during surgery.

The Dutch trial showed that short term preoperative radiotherapy associated with surgery with TME have a significant impact in decreasing local recurrence, from $10.9 \%$ to $5.6 \%$ compared to surgical treatment alone [9]. The long term preoperative radiotherapy (FFCD 9203 trial; EORTC 22921 trial) showed a significant difference in local recurrence rate (5 years) which has dropped to $8.1 \%$ when chemotherapy is associated [10,11].

\section{2) Downstaging}

Neoadjuvant chemoradiation therapy (CRT) for distal rectal cancer has resulted in significant tumor downstaging and downsizing, including complete tumor regression. By switching the tumor in a lower stage, it is possible to achieve resection of a locally non resecable tumor. Downstaging after preoperative radiotherapy is dependent on the fraction size, total dose applied and the time interval between the first dose of radiotherapy and the date of surgery. Evans et al. [12] demonstrated increased rectal cancer downstaging when the interval between preoperative radiation and surgery had been more than 8 weeks.

\section{3) Sphincter saving surgery}

According to different trials [3,9,1317], rectal tumor shrinkage after neoadjuvant therapy (radio-chemotherapy) increase the possibility of applying a surgical technique to preserve the anal sphincter (low anterior resection rather than abdominoperineal resection) and an important effect on quality of life. The chance of sphincter saving surgery was increased also by reassessment of the rule of the $5 \mathrm{~cm}$ or even $2 \mathrm{~cm}$ for distal margin $[18,19]$.

The Lyon R90-01 randomized trial comparing a short versus a long interval preoperative radiotherapy, demonstrated an increase in tumor response with long interval (sterilized operative specimen $15 \%$ versus $5 \%$ ) and a trend toward more sphincter saving surgery in low rectal cancer $(41 \%$ versus $22 \%$ ) [20].

\section{FRACTION SIZE AND DOSE}

The recommended dose for long schedule radiotherapy in rectal cancer is 50 Gy, which is conventionally fractionated in 1.8-2.0 Gy. A mathematical model is used to calculate the biological equivalent dose (BED) of various treatment schemes [21]:

$$
B E D=n d(1+d /(\alpha / \beta))-\gamma / \alpha(T-T k)
$$

where $n=$ number of fractions, $d=$ dose per fraction in Grays; $T=$ duration of radiotherapy in days, $T k=$ time until repopulation starts.

The sensitivity of tissue is represented by $\alpha / \beta$ and, for the rectal tumor cells, is considered to be $10 \mathrm{~Gy}$. It is supposed that repopulation with tumor cells starts after 7 days and that subsequent loss of efficiency $(\gamma / \alpha)$ is 0.6 Gy/day. These calculations explained the using of the fractionation schedule $5 \times 5$ Gy with the highest biological equivalent dose of rectal tumor cells.

\section{FOCUS SITES FOR RADIO-} THERAPY IN RECTAL CANCER

An important part of the radiation treatment planning is to establish the region 
of interest for the irradiation. In rectal cancer, during the preoperative radiotherapy, the small bowel is the most important organ at risk, with adverse effects such as acute radiation enteritis or late toxicity (e.g. chronic diarrhea, bowel stricture, perforation and hemorrhage) [22,23]. The development of these reactions was highly correlated with the dose and volume of small bowel irradiation [24]. This risk can be reduced by reducing the irradiated volume small bowel. One of the methods for reduction in the volume of small bowel irradiated is the Intensity Modulated Radiation Therapy (IMRT). According to this method, it is possible to characterize the position and motion of the small bowel, which is the primary dose-limiting structure [25]. The target volume can vary due to rectum and bladder motion, depending on their state of fullness.

Another important factor in defining the area of interest for irradiation in rectal cancer is the location of local recurrence. Clinical investigations shows that the frequently sites of loco-regional recurrence can be classified into one of four categories: 1) low pelvis: below the top of the acetabulum; 2) mid pelvis: from the top of the acetabulum to the bottom of the sacroiliac joint; 3) high pelvis: above the bottom of the sacroiliac joint; 4) presacral: within $2 \mathrm{~cm}$ anterior to the sacrum. [26]

The radiotherapy planning was revolutionized by the ability to delineate tumors and adjacent normal structures in three dimensions using specialized CT and / or MRI and planning software. Virtual simulation, the most basic form of planning, allows more accurate placement of radiation beams than is possible using conventional $\mathrm{X}$-rays, where soft tissue structures are often difficult to assess and normal tissues difficult to protect.

The computed tomography (CTscans) is used to define a clinical target volume (CTV), in order to be submitted to external radiotherapy. This simulation of the regions of interest is derived from the Pinnacle planning system (Philips Radiation
Oncology Systems). This system allows the user to visualize actual patient anatomy based on the information provided by the $3 \mathrm{D}$ data set. It also eliminates the need to contour structures such as skin and bone to visualize in 3D [27]. This planning system performs the following:

- define the region of interest, which is automatic isocenter placement;

- define beam sizes and orientations;

- shape the blocks with automatic margins;

- dose grid resolution;

- treatment prescriptions;

- isodose normalization;

- dose volume histograms setup.

The images from the simulation help the doctor to locate the tumor and better identify the treatment area. This CTV is performed in the prone position and vesical repletion and contain the rectum and perirectal tissues plus the regional lymphatics (Fig. 1).
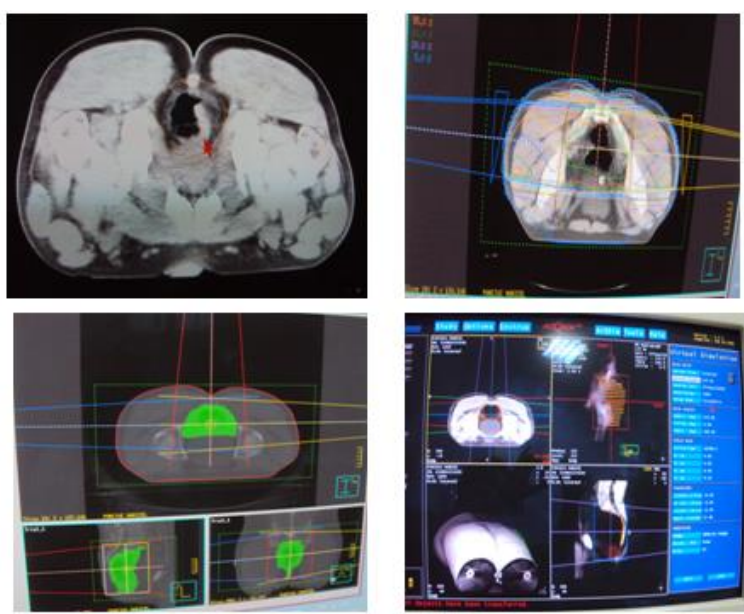

Fig. 1 Determining the clinical target volume for neoadjuvant radiotherapy in rectal cancer

[Clinac Linear Accelerator 2100; $10 \mathrm{MV}$ photons] (Regional Institute of Oncology Iaşi, Romania)

For middle and lower rectum tumor, the CTV is accounted by the mesorectum. The limits are represented beyond by the sacro-recto-genito-pubic layers and inside by the superior pelvirectal spaces. Backward, the plan comes in contact with sacral concavity and above with the anterior rectal shell, which is represented by Denonvilliers fascis in man and the recto-vagina fascis in 
women. Upper, the limit of irradiation plan is made by the $S_{3}$ vertebrae. Below, the CTV must stop at $1 \mathrm{~cm}$ under the anorectal junction, corresponding to the anal sphincter.

For the tumors located in the upper rectum, the irradiation area is defined as follows: upper: the plane of $3 \mathrm{~cm}$ below the inferior pole of the tumor; sideways: $3 \mathrm{~cm}$ from the rectal wall anteriorly and on the lateral sides; backward: $3 \mathrm{~cm}$ from the rectal wall or in contact with sacral or vertebral bone structures if this distance is less than 3 $\mathrm{cm}$.

When the rectal tumor is locally advanced, with regional invasion of neighbor organs (sacrum, bladder, vagina, uterus, prostate), the irradiated region should include these areas and must exceed $5 \mathrm{~mm}$ beyond the region.

The target irradiation volume should include the corresponding lymphatic drainage areas for the invaded organs: the upper pelvirectal space, the ischio-rectals fossa, the seminal vesicles and the prostate for men and the posterior vagina wall for women. For the lower rectal tumor, the internal iliac lymph nodes should be included in the CTV.

All these items are important in determining a target volume to be submitted to irradiation. Nuyttens et al. [25] showed that CVT variations are unequal in all 3 planes. The authors recommend that the target volume should be extended with $1 \mathrm{~cm}$ above the tumor plane in order to create a target volume that covers the anatomoclinical target volume. The acquisition of detailed computerized tomography (CT) imaging at the time of simulation, along with three-dimensional (3D) treatment planning software has been integrated with radiation delivery hardware to create the modality known as 3D conformal radiotherapy (3DXRT).

\section{CONCLUSION}

Preoperative radiotherapy associated with total mesorectal excision reduces the risk of local recurrence in rectal cancer. The radiotherapy planning was revolutionized by the ability to delineate tumors and adjacent normal structures in three dimensions using specialized CT and / or MRI and planning software. When the treatment volume conforms to the shape of the tumor, the relative toxicity of radiation on surrounding normal tissues is reduced, allowing a higher radiation dose to be delivered to the tumor. The definition of the CTV which includes both tumor and lymphatic drainage areas, depending on tumor site, require a simulation procedure that takes into account multiple factors: tumor position, degree of local invasion, movement of the rectum, the fullness of neighbor organs, the position and motion of the small bowel.

\section{NOTE}

Corresponding author is a $\mathrm{PhD}$ student of University of Medicine and Pharmacy "Gr.T. Popa"Iaşi. This paper is the result of doctoral internship documentation of the project "Doctoral fellowships for the increase of competitiveness in the medical and pharmaceutical field" of University of Medicine and Pharmacy "Gr.T. Popa" Iaşi, HRD / 88 / 1.5 / S / 58965.

\section{CONFLICT OF INTEREST}

Authors have no conflict of interest to declare.

\section{REFERENCES}

1. Ferlay J, Shin HR, Bray F, Forman D, Mathers C, Parkin DM., GLOBOCAN 2008 v1.2, Cancer Incidence and Mortality Worldwide: IARC CancerBase No. 10. Lyon, France: International Agency for Research on Cancer; 2010. [Available at: http://globocan.iarc.fr, accessed on 26/mars/2012].

2. Ferlay J, Parkin DM, Steliarova-Foucher E. Estimates of cancer incidence and mortality in Europe in 2008. European Journal of Cancer. 2010; 46: 765-781.

3. Sauer R, Becker H, Hohenberger $W$, et al. Preoperative versus postoperative chemoradiotherapy for rectal cancer. $N$ Engl J Med. 2004; 351: 1731-1740.

4. Tepper JE, Cohen AM, Wood WC, Orlow EL, Hedberg SE Postoperative radiation therapy of rectal cancer. Int J Radiat Oncol Biol Phys 1987; 13(1): 5-10 
5. First Report of an MRC Working Party. A trial of preoperative radiotherapy in the management of operable rectal cancer. $\mathrm{Br} J$ Surg.1982; 69(9): 513-519.

6. Boulis-Wassif S, Gerard A, Loygue J, Camelot D, Buyse M, Duez N. Final results of a randomized trial on the treatment of rectal cancer with preoperative radiotherapy alone or in combination with 5-fluorouracil, followed by radical surgery. Trial of the European Organization on Research and Treatment of Cancer Gastrointestinal Tract Cancer Cooperative Group. Cancer.1984;53 (9): 1811-1818

7. *** Swedish Rectal Cancer Trial, Improved survival with preoperative radiotherapy in resectable rectal cancer. $N$ Eng J Med. 1997; 336(14): 980-987.

8. Bujko K, Nowacki MP, NasierowskaGuttmejer A. et al. Sphincter preservation following preoperative radiotherapy for rectal cancer: report of a randomised trial comparing short-term radiotherapy vs.conventionally fractionated radiochemotherapy. Radiother Oncol. 2004; 72(1): 15-24.

9. Kapiteijn E, Marijnen CA, Nagtegaal ID, et al. Preoperative radiotherapy combined with total mesorectal excision for resectable rectal cancer. N Engl J Med. 2001; 345(9): 638-646.

10. Bosset JF, Collette L, Calais G, et al. Chemotherapy with preoperative radiotherapy in rectal cancer. $N$ Engl J Med. 2006; 355: 1114-1123.

11. Peeters KC, Marijnen CA, Nagtegaal ID, et al. The TME trial after a median follow-up of 6 years: increased local control but no survival benefit in irradiated patients with resectable rectal carcinoma. Ann Surg. 2007; 246: 693-701.

12. Evans J, Tait D, Swift I, et al. Timing of surgery following preoperative therapy in rectal cancer: the need for a prospective randomized trial? Dis Colon Rectum. 2011; 54: 1251-1259.

13. Minsky BD. Adjuvant therapy for rectal cancer - a good first step. N Engl J Med. 1997; 336: 1016-1017.

14. Valentini V, Glimelius B, Minsky BD, et al. The multidisciplinary rectal cancer treatment: main convergences, controversial aspects and investigational areas which support the need for an European Consensus. Radiother Oncol. 2005; 76: 241-250.

15. Francois $Y$, Nemoz CJ, Bauliex $J$, et al. Influence of the interval between preoperative radiation therapy and surgery on downstaging and on the rate of sphincter-sparing surgery for rectal cancer: the Lyon R90-01 randomized trial. J Clin Oncol. 1999; 17: 2396-23402.
16. Bujko K, Nowacki MP, Nasierowska-Guttmejer A, et al. Sphincter preservation following preoperative radiotherapy for rectal cancer: Report of randomised trial comparing shortterm radiotherapy vs conventionally fractionated radiochemo-therapy. Radiother Oncol. 2004; 72: 15-24.

17. Gerard JP, Chapet O, Nemoz C, et al. Improved sphincter preservation in low rectal cancer with high dose preoperative radiotherapy: the Lyon R96-02 randomized trial. J Clin Oncol. 2004; 22: 2404-2409.

18. Bujko K, Rutkowski A, Chang G, Michalski W, Chmielik E. Is the $1 \mathrm{~cm}$ rule of distal bowel resection margin in rectal cancer based on clinical evidence? A systematic review. Ann Surg Oncol. 2012; 19: 801-808.

19. Rutkowski A, Nowacki MP, Chwalinski M, et al. Acceptance of a $5 \mathrm{~mm}$ distal bowel resection margin for rectal cancer: is it safe? Colorectal Disease. 2011; 14: 71-78.

20. Francois Y, Nemoz C, Baulieux J, et al Influence of the interval between preoperative radiation therapy and surgery on downstaging and on the rate of sphincter saving surgery for rectal cancer: The Lyon $\mathrm{R} 90.01$ randomized trial. J Clin Oncol. 1999; 17: 2396-2402.

21. Fowler JF. The linear-quadratic formula and progress in fractionated radiotherapy. $\mathrm{Br} J$ Radiol. 1989; 62: 679-694.

22. Minsky B, Conti J, Huang Y, et al. Relationship of acute gastrointestinal toxicity and the volume of irradiated small bowel in patients receiving combined modality therapy for rectal cancer. $J$ Clin Oncol. 1995; 13: 1409-1416.

23. Letschert J, Lebesque J, de Boer R, et al. Dose volume correlation in radiation related late small bowel complications: a clinical study. Radiother Oncol. 1990; 18: 307-320.

24. Baglan KL, Robertson JM, Frazier RC, A CTbased analysis of the relationship between acute grade 3 small bowel toxicity and the volume of small bowel irradiated in patients receiving concurrent chemoradiotherapy for rectal cancer. Int J Radiat Oncol Biol Phys. 2000; 48 (s): 224.

25. Nuyttens JJ, Robertson JM, Di Y, Martinez AA. The small bowel position during adjuvant radiation therapy for rectal cancer. Int J Radiat Oncol Biol Phys. 2000; 48(suppl. 3): 226.

26. Yu TK, Bhosale PR, Crane $\mathrm{CH}$, et al. Patterns of locoregional recurrence after surgery and radiotherapy or chemoradiation for rectal cancer. Int J Radiat Oncol Biol Phys. 2008; 71(4): 1175-1180.

27. Bedford JL, Childs PJ, Nordmark Hansen V, Mosleh-Shirazi MA, Verhaegen F, Warrington AP. Commissioning and quality assurance of the Pinnacle3 radiotherapy treatment planning system for external beam photons. The British Journal of Radiology. 2003; 76: 163-176. 
